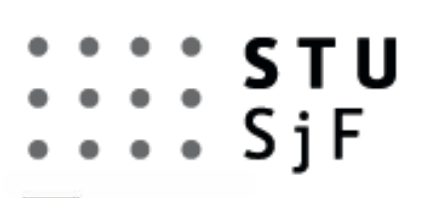

DE GRUYTER .

Print ISSN 0039-2472

On-line ISSN 2450-5471

\section{Journal of MECHANICAL ENGINEERING}

- Strojnícky časopis

VOLUME 65, NO 1, 2015

pp. $21-26$

DOI:10.1515/scjme-2016-0002

\title{
CYCLIC PLASTIC PROPERTIES OF CLASS C STEEL EMPHASIZING ON RATCHETING: TESTING AND MODELLING
}

\author{
R. HALAMA ${ }^{1}$, A. MARKOPOULOS ${ }^{1}$, M. ŠOFER ${ }^{2}$, Z. PORUBA ${ }^{2}$, P. MATUŠEK $^{3}$ \\ ${ }^{I} V \check{S} B$-Technical University of Ostrava, Department of Applied Mechanics, Faculty of Mechanical Engineering, \\ Centre of Excellence IT4Innovations, 17.listopadu 15, Ostrava, Czech Republic; email: radim.halama@vsb.cz, \\ alexandros.markopoulos@vsb.cz \\ ${ }^{2} V \check{S} B$-Technical University of Ostrava, Department of Applied Mechanics, Faculty of Mechanical Engineering, \\ 17.listopadu 15, Ostrava,Czech Republic; email: michal.sofer@vsb.cz, zdenek.poruba@vsb.cz \\ ${ }^{3}$ Bonatrans Group, Bohumín, Revolučni 1234, 735 94, Czech Republic; email: pmatusek@bonatrans.cz
}

KEYWORDS: cyclic plasticity, ratcheting, FEM, low-cycle fatigue, wheel steel.

\section{Introduction}

Cyclic plasticity modelling of metals needs individual approach. There are specific theories for various metallic materials including mainly phenomenological models, useful for practical applications [1]. However, a robust cyclic plasticity model with higher number of parameters, which should be estimated using a large amount of experimental fatigue test data, is often required for correct description of material behaviour. It is true mainly for case of stress controlled loading with non-zero mean stress value, when cyclic creep or so called ratcheting occurs. The ratcheting effect can be described as an accumulation of any component of strain tensor with increasing number of cycles. It was recognized [2 - 3], that cyclic plasticity models recently included in common commercial FE programs (namely overlay Besseling model [4] and Armstrong-Frederick type model of Chaboche [5]) cannot correctly describe ratcheting under uniaxial and non-proportional multiaxial loading simultaneously and cannot capture non-proportional hardening, non-Masing's behavior and other important effects of cyclic plasticity. The problem can be solved by implementing a more complex cyclic plasticity model into a FE code, see publications [6] and [7].

This paper is focused on the stress-strain behaviour of the Class $\mathrm{C}$ steel in cyclic plastic domain and its FE simulation. An experimental study on the wheel steel specimens including uniaxial as well as multiaxial tests has been realized in the laboratory at Department of mechanics of materials of VŠB-TU Ostrava. The MAKOC model applied in simulations gives very good prediction of ratcheting in all solved cases.

\section{Description of experimental study}

The main attention in this study was paid o study ratcheting under non-proportional loading. The specimens were subjected to tension-torsion tests on the reconstructed testing machine INOVA $100 \mathrm{kN} / 1000 \mathrm{Nm}$ (Fig.1) as in the previous study, performed on ST52 steel [8]. The extensometer EPSILON 3550 with $25.4 \mathrm{~mm}$ gauge length was used to measure axial and shear strain simultaneously. The testing specimen has tubular testing part with outer 
diameter of $12.5 \mathrm{~mm}$ and with inner diameter of $10 \mathrm{~mm}$. The specimen was used also for the case of uniaxial loading.

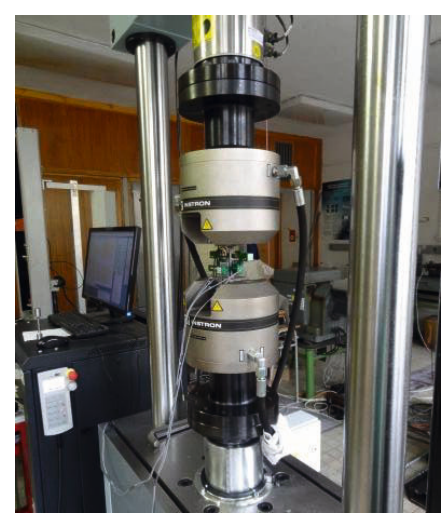

Fig. 1. Biaxial fatigue testing machine.

Performed uniaxial multistep test under strain rate of $0.01 \mathrm{~s}^{-1}$ has revealed a cyclically stable behaviour of the steel under higher amplitude of loading. Figure 2 shows uniaxial hysteresis loops obtained from uniaxial multistep test, whereas figure 3 displays resulting cyclic stress-strain curve from mentioned tests.

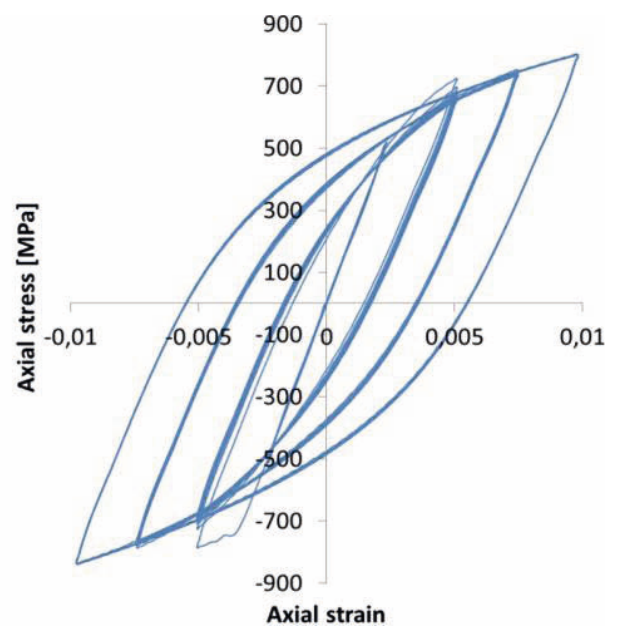

Fig. 2. Results of push-pull multistep test.

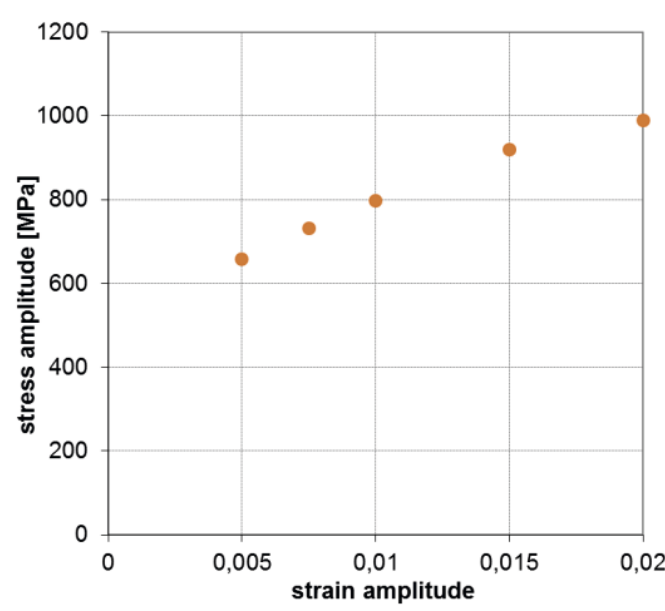

Fig. 3. Cyclic stress-strain curve from multistep tests.

There was applied the load path (Fig.4) in accordance to McDowell's experiments [9] in the tension/compression-torsion tests to obtain similar stress-strain history as in a point on the surface under rolling-sliding line contact case. All multiaxial force controlled tests were realized under sinusoidal wave loading with frequency of $0.1 \mathrm{~Hz}$.

Figure 4 contains results from the multiaxial ratcheting test, which was obtained by the symmetric tension/compression and by repeated torsion. The case with axial stress magnitude of $700 \mathrm{MPa}$ and shear stress magnitude of $400 \mathrm{MPa}$ was realized for the wheel steel Class $\mathrm{C}$. As the consequence of the repeated torsion applied to the specimen, the increase of the shear strain occurs cycle by cycle in the same direction as the torque is applied.

Three step loading test was also realized to study influence of load level on shear strain accumulation with the same ratio of maximal axial stress and maximal shear stress. 
The load history as well as strain response are shown in the Fig.5 and Fig.6 respectively.

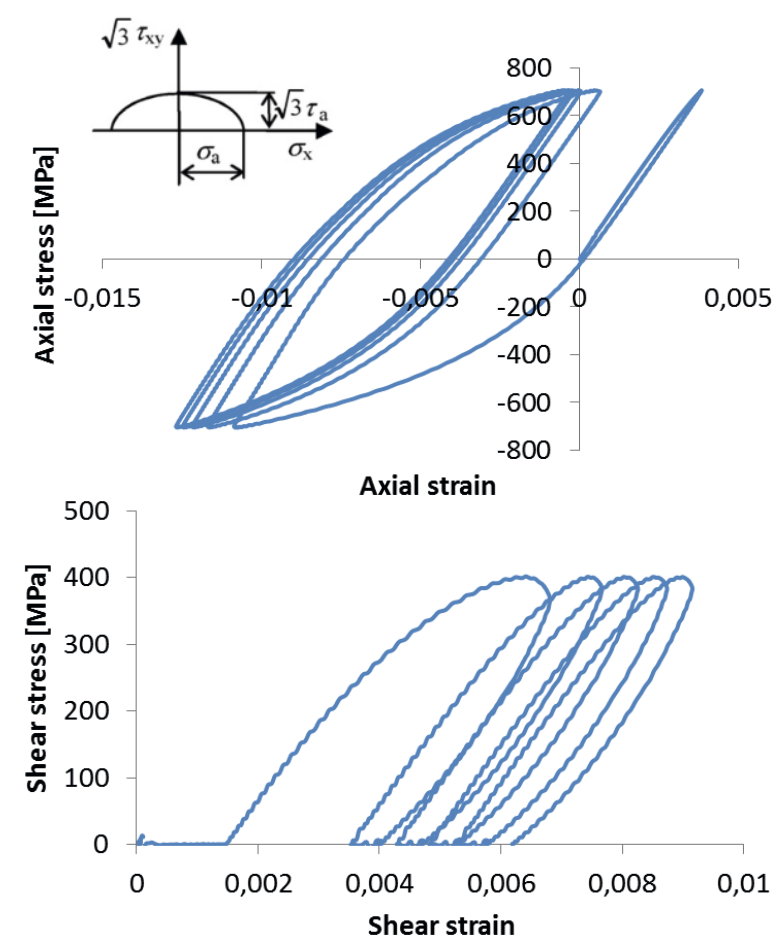

Fig. 4. Results of multiaxial ratcheting test.

Ratcheting phenomenon has been investigated also under uniaxial loading. The Fig.7 illustrates the accumulation of axial strain due to non-zero mean stress. The axial stress amplitude is $645 \mathrm{MPa}$ and the axial mean stress is $155 \mathrm{MPa}$. The material exhibits steady state after completion of transient behavior. This is also evident from Fig.7.

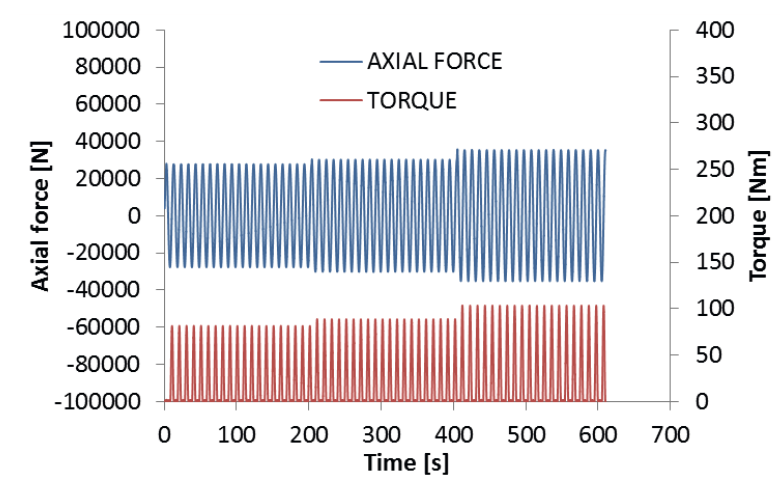

Fig. 5. Load history in McDowell's multistep test.

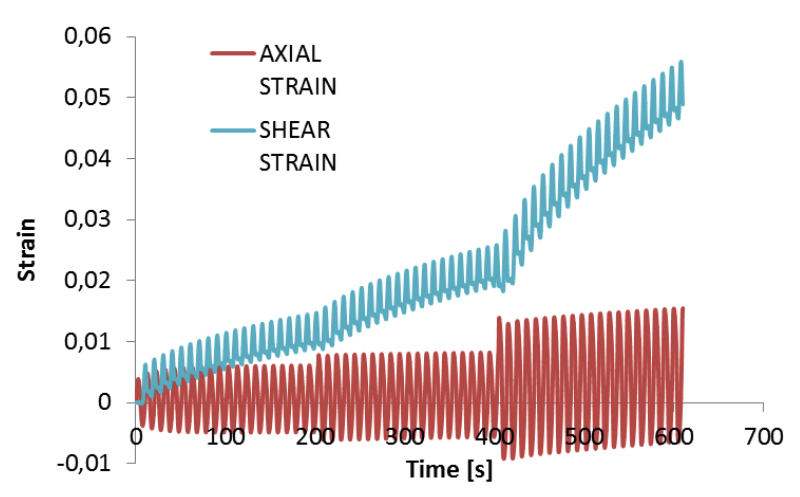

Fig. 6. Strain response in McDowell's multistep test. 


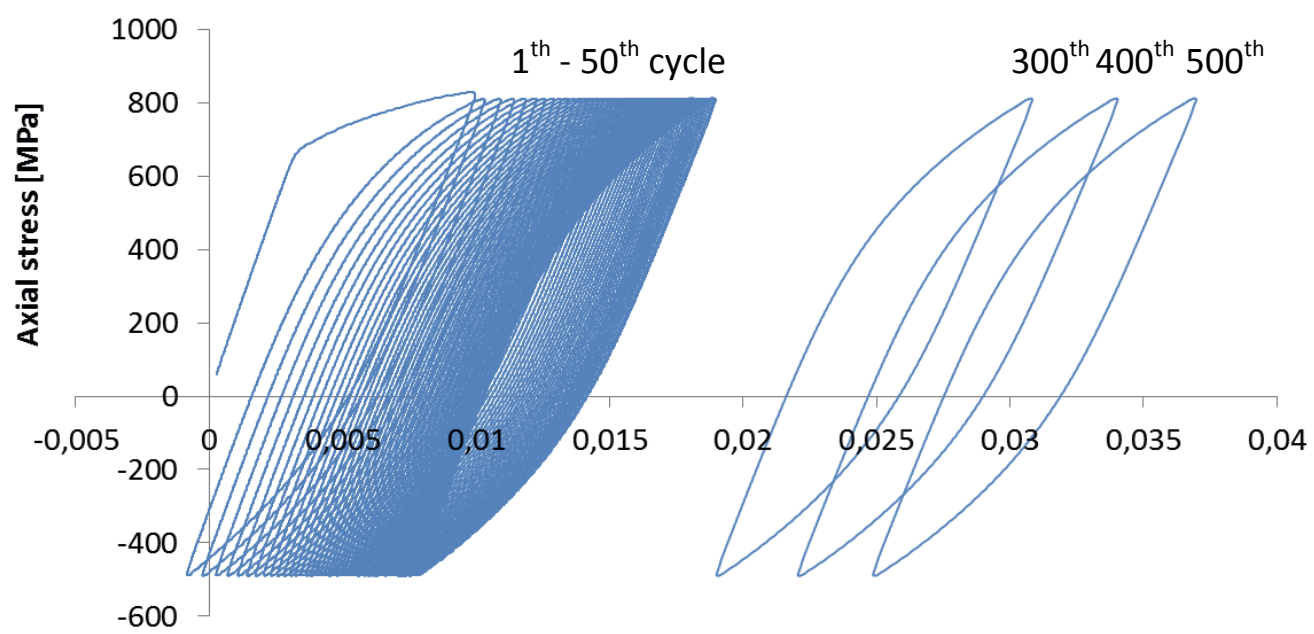

Axial strain

Fig. 7. Results of uniaxial ratcheting test.

\section{Finite element simulations}

The reduced version of MAKOC model [10] has been applied in subsequent finite element simulations. The cyclic plasticity model is based on AbdelKarim-Ohno kinematic hardening rule

$$
\boldsymbol{\alpha}=\sum_{i=1}^{5} \boldsymbol{\alpha}_{i}, \quad \dot{\boldsymbol{\alpha}}_{i}=\frac{2}{3} C_{i} \dot{\boldsymbol{\varepsilon}}_{\mathbf{p}}-\mu_{i} \gamma_{i} \boldsymbol{\alpha}_{i} \dot{p}-\gamma_{i} H\left(f_{i}\right)\left\langle\dot{\lambda}_{i}\right) \boldsymbol{\alpha}_{i}, \quad f_{i}=\frac{3}{2} \boldsymbol{\alpha}_{i}: \boldsymbol{\alpha}_{i}-\left(\frac{C_{i}}{\gamma_{i}}\right)^{2}, \dot{\lambda}_{i}=\dot{\boldsymbol{\varepsilon}}_{\mathbf{p}}: \frac{\boldsymbol{\alpha}_{i}}{C_{i} / \gamma_{i}}-\mu_{i} \dot{p},
$$

where $H\left(f_{i}\right)$ is Heavisides step function and the symbol $\langle x\rangle$ means Macaulay's bracket $(\langle x\rangle=x+|x|)$, and Calloch isotropic hardening rule

$$
\dot{R}=b(Q-R) \dot{p}, \dot{Q}=d \cdot A \cdot\left(Q_{A S}(A)-Q\right) \dot{p}, Q_{A S}(A)=\frac{g A Q_{\infty}}{g A+(1-A)}, A=1-\frac{(\mathbf{a}: \mathbf{a})^{2}}{(\mathbf{a}: \mathbf{a})(\mathbf{a}: \mathbf{a})} .
$$

The isotropic hardening rule can capture the effect of non-proportional hardening. Material parameters of kinematic hardening rule $C_{i}$ and $\gamma_{i}$ were identified from a large hysteresis loop with strain range of $2 \%$. All other parameters were calibrated from the multiaxial ratcheting test. Material parameters of the cyclic plasticity model, used in all simulations are shown in the Table 1.

Table 1 Material parameters.

$$
\begin{gathered}
\sigma_{Y}=400 M P a ; E=205000 M P a ; \mu=0.3 ; \gamma_{1-5}=2222,690,215,103,67 ; \\
C_{1-5}=190234,86250,22463,7478,13810 M P a \\
d=1 ; b=10 ; Q_{\infty}=50 M P a ; g=0.2 ; \mu_{i}=0.12 \quad \text { for all } i
\end{gathered}
$$

All finite element analyses were performed using program Ansys, where the constitutive equations were implemented. Firstly, the uniaxial multistep test was simulated and compared with experimental results, see Fig. 8 and 9. 


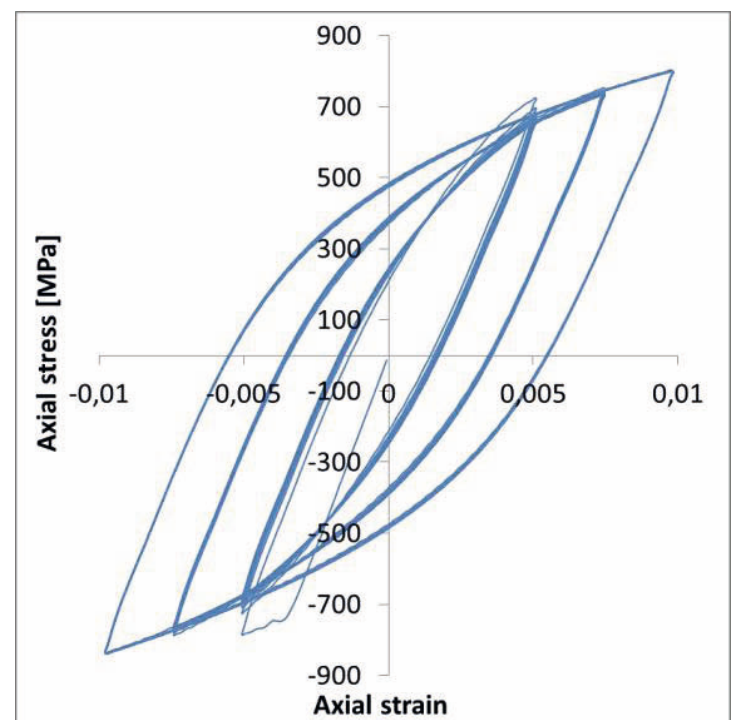

Fig. 8. Uniaxial multistep test - experiment.

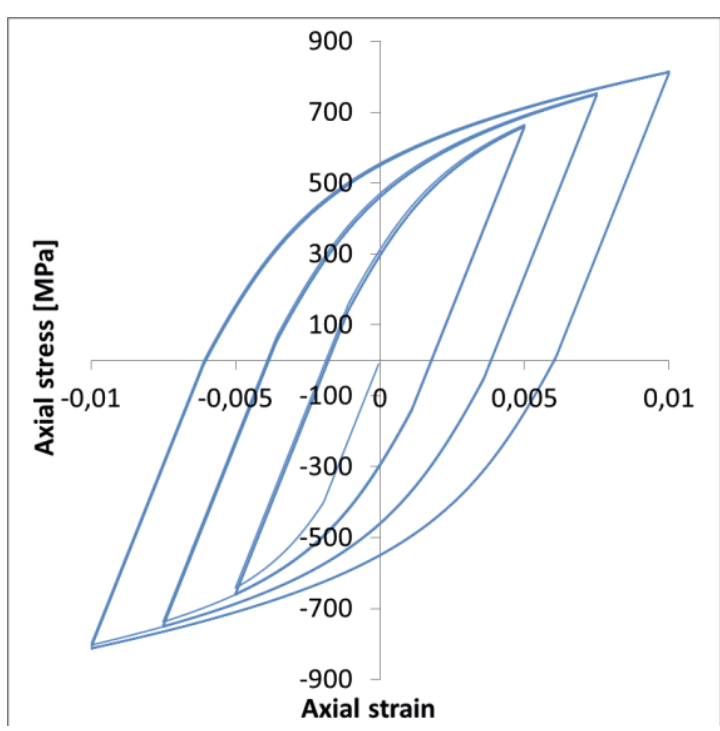

Fig. 9. Uniaxial multistep test - prediction.

The ratcheting prediction from the simulation of uniaxial ratcheting test show good correspondence with experiment in the sense of accurate ratcheting rate prediction after 20 cycles, which is clear from the Fig. 10.

The multiaxial ratcheting test conducted under non-proportional loading accordingly to McDowell was simulated by FEM too. The main result is shown in the Fig.11 in the form of shear strain accumulation diagram.

It is clear, that the kinematic hardening rule of AbdelKarim-Ohno makes possible good prediction of ratcheting for the solved cases. The ratcheting rate is well predicted mainly in steady state, after stabilization of the strain response.

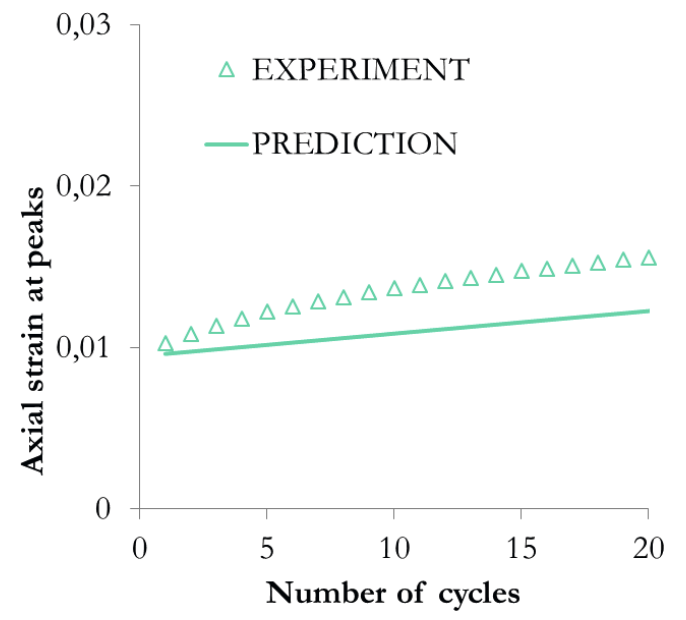

Fig. 10. Comparison of ratcheting prediction with experiment uniaxial loading.

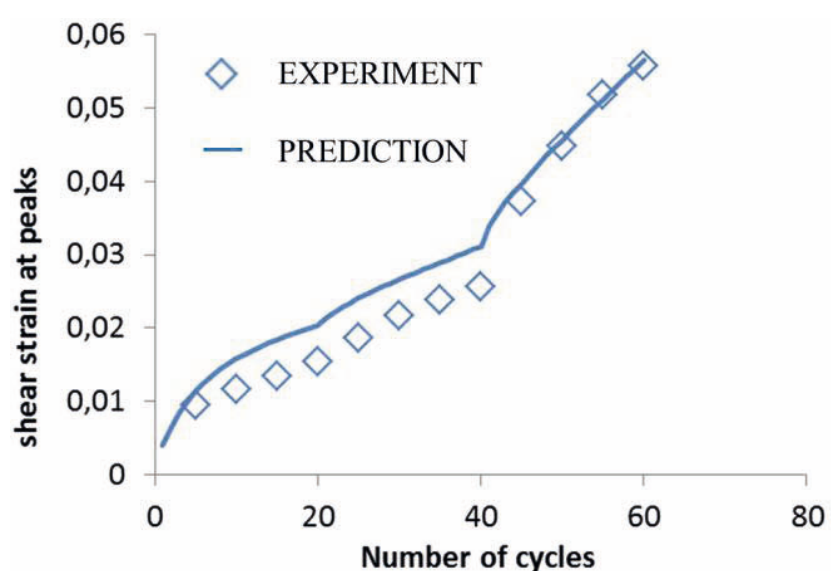

Fig. 11. Comparison of ratcheting prediction with experiment - multiaxial loading. 


\section{Conclusions}

There were presented some interesting results of realized uniaxial and multiaxial experiments, including such important effects as ratcheting and non-proportional hardening. Developed cyclic plasticity model called MAKOC [10] was successfully applied in the FEM simulations for chosen cases to describe the stress-strain behaviour of examined wheel steel correctly. The numerical results show very good prediction of stress-strain material behaviour under uniaxial strain controlled loading as well as stress controlled loading. The uniaxial and multiaxial ratcheting can be described simultaneously and accurately by the AbdelKarimOhno kinematic hardening rule because of steady state ratcheting of the material Class $\mathrm{C}$. The influence of shear stress magnitude and mean shear stress was well described by the cyclic plasticity model in the simulation of McDowell test.

This type of fatigue test will be realized to compare ratcheting resistance of several materials for wheel sets production in a future work.

Acknowledgement: This work was supported by the European Regional Development Fund in the IT4Innovations Centre of Excellence project (CZ.1.05/1.1.00/02.0070), and by the Grant Agency of the Czech Republic (GACR) project No. 15-18274S. This work was also supported by Czech Regional Operational Program ROP NUTS II under solution of Project No. CZ.1.10/2.2.00/16.01386 with BONATRANS GROUP company financial support.

\section{REFERENCES}

[1] HALAMA, R., SEDLÁK, J., ŠOFER, M.: Phenomenological Modelling of Cyclic Plasticity, Chapter in: P. Miidla (Ed.), Numerical Modelling, InTech, Rijeka, 2012, pp. 329-354.

[2] RAHMAN, S. M., HASSAN, T., CORONA, E.: Evaluation of Cyclic Plasticity Models in Ratcheting Simulation of Straight Pipes under Cyclic Bending and Steady Internal Pressure, Int. J. of Plast. 24, No. 10, 2008, pp. 1756-1791.

[3] HALAMA, R.: Experimental Facts and Phenomenological Modelling of Cyclic Plasticity of Metals, Habitation work in Applied mechanics Faculty of Mechanical Engineering VŠB-TU Ostrava, 2009. pp. 141 [http://www.339.vsb.cz/PDF/PUBLIKACE/RH_habilitace.pdf] (in Czech)

[4] BESSELING, J. F.: A Theory of Elastic, Plastic, and Creep Deformations of an Initially Isotropic Material Showing Anisotropic Strain-Hardening, Creep Recovery, and Secondary Creep, Journal of Applied Mechanics, 1958, vol. 25, pp. 529-536.

[5] CHABOCHE., J. L., DANG VAN, K., CORDIER, G.: Modelization of The Strain Memory Effect on The Cyclic Hardening of 316 Stainless Steel, in 5th International Conference on Structural Mechanics in Reactor Technology, Division L11/3, Berlin, 13.-17. August 1979, Ed. Jaeger A and Boley B A. Berlin: Bundesanstalt für Materialprüfung, pp. 1-10.

[6] HALAMA, R.: A Modification of AbdelKarim-Ohno Model for Ratcheting Simulations. Technical Gazette, 2008, vol. 15, n.3, ISSN 1330-3651, pp.. 3-9 .

[7] HALAMA, R.: Rolling Contact Simulations with Various Cyclic Plasticity Models, in Proceedings of Ansys Conference \& 25th CADFEM Users' Meeting, Dresden, 21-23 november 2007. [CD-ROM], ISBN 3-937523-04-9.

[8] HALAMA, R., FOJTÍK, F., MARKOPOULOS, A.: Memorization and Other Transient Effects of ST52 Steel and Its FE Description, Applied Mechanics and Materials 486, 2013, pp. 48-53.

[9] MCDOWELL, D., L.: Stress state dependence of cyclic ratchetting behaviour of two rail steels. International Journal of Plasticity 11, 1995, pp. 397-421.

[10] HALAMA, R., ŠOFER, M., FOJTÍK, F.: Choice and Calibration of Cyclic Plasticity Model with Regard to Subsequent Fatigue Analysis. Engineering Mechanics 19, 2012, pp.87-97. 